\title{
Indications, patient selection and timing of referral for lung transplantation
}

\author{
A.R. Glanville*, M. Estenne ${ }^{\#}$
}

Indications, patient selection and timing of referral for lung transplantation. A.R. Glanville, M. Estenne. (C) ERS Journals Ltd 2003.

ABSTRACT: Lung transplantation (LTx) is now generally accepted as a useful modality of care for patients with severe life-threatening respiratory diseases that are refractory to other medical or surgical therapies. With the huge development of LTx over the last $15 \mathrm{yrs}$, the disparity between the number of potential recipients and the number of donor organs available has become a major constraint, with many patients dying on the waiting lists. Therefore, it is of primary importance to control and optimise the use of this limited organ resource by weighting the risks and benefits of transplantation in individual patients, and to identify those patients who have a better chance of having a favourable outcome with transplantation.

This article discusses the selection process of potential candidates and the currently accepted absolute and relative contraindications, and proposes general and diseasespecific recommendations for optimising the timing of referral. Early referral for consideration of lung transplantation is highly desirable as it enhances the patient's chance of surviving to transplant and allows the transplant team to actively manage identified comorbidities during the waiting period.

Eur Respir J 2003; 22: 845-852.
*The Lung Transplant Unit, St Vincent's
Hospital, Sydney, New South Wales, Australia. ${ }^{\#}$ The Chest Service, Erasme University Hospital, Brussels, Belgium.

Correspondence: A.R. Glanville, The Lung Transplant Unit, Xavier 4, St Vincent's Hospital, Victoria Street, Darlinghurst, Sydney NSW 2010, Australia.

Fax: 61293324267

E-mail: aglanville@stvincents.com.au

Keywords: Indications

lung transplantation

referral

selection criteria

Received: April 82003

Accepted: April 92003
Lung transplantation (LTx) is now generally accepted as a useful modality of care for patients with severe lifethreatening respiratory diseases that are refractory to conventional therapies. With the huge development of LTx over the last $15 \mathrm{yrs}$, the disparity between the number of potential recipients and the number of donor organs available has become a major constraint, with many patients dying on the waiting lists. Therefore, it is of primary importance to control and optimise the use of this limited organ resource by weighing the risks and benefits of transplantation in individual patients, and to identify those patients who have a better chance of a favourable outcome with transplantation.

In 1998, transplant physicians and surgeons representing five international societies agreed on a document providing guidelines to identify potential candidates for LTx [1]. Since the promulgation of this document, additional data regarding the selection and timing of referral have become available. Thus, it is appropriate to discuss these new data in context with the original proposals. Although the selection process for LTx is not standardised among programmes, it is the responsibility of the transplant community to develop quality evidence to guide practice, so that the majority of patients who may benefit from these disciplines are assessed sufficiently early in their disease course to allow an optimum chance of surviving to LTx. In addition to considering absolute and relative contraindications to $\mathrm{LTx}$, this article discusses factors that may predict survival and may be used in

$\overline{\text { For editorial comments see page } 721 .}$ the decision-making process as to when a patient should be referred and listed for LTx. Specific selection criteria for recipients of living-donor lung transplants, for paediatric patients and for recipients of a second transplant are not addressed in this article.

\section{Patient selection}

LTx is indicated for patients with end-stage lung diseases who demonstrate declining function despite optimal therapy. Candidates should have a chronic disease that is refractory to other medical or surgical therapies and for which survival is limited (see below). Critically ill patients in desperate clinical situations are rarely appropriate candidates for LTx.

\section{Selection process}

There are surprisingly few data in the literature describing the process of patient selection, though it is of fundamental importance to the outcomes achieved by individual programmes. Formats vary from protocol-driven multidisciplinary assessments to largely single operator-determined decisions of whom to list and when. The original Stanford University Medical Center, Stanford, CA, USA, model comprised a rigorous process of preliminary review of the medical history and a comprehensive set of predetermined investigations by the senior transplant fellow prior to commitment to onsite evaluation; this model was designed both to educate the potential recipient regarding LTx and 
identify any medical or psychological areas that may benefit from targeted interventional strategies [2]. Following this period of review, the prospective recipient met a senior medical team member (usually the chief of transplant surgery) whose responsibility was to accept, reject or defer the patient for active listing.

The advent of larger services has seen the development of larger team meetings to subserve the same responsibility, and allow a balanced assessment of the myriad factors that may potentially impact on post-transplant outcomes [3]. At the University of Groningen in the Netherlands, a similar stepwise process has been followed [4]. The responsible body making the decisions regarding suitability for listing was the multidisciplinary LTx meeting that was held weekly. Review of the initial written referral saw $14 \%$ of patients rejected and $2 \%$ deferred because they had not reached the "transplant window" [2]. Following a first visit to the outpatient clinic, a further $11 \%$ were rejected and $18 \%$ deferred. After inpatient evaluation, another 5\% were rejected. In all, $37 \%$ of referred patients achieved active listing status, $20 \%$ of whom died waiting for a donor. The stepwise selection process utilised helps to identify patients with potential complications at an early stage and thereby avoid both the development of unrealistic expectations and the expense of unnecessary investigations.

From a practical perspective, patient selection involves analysis of standard investigations (table 1) designed to identify comorbidities that may increase risk (table 2), and balancing those against likely outcomes. Age alone should not dictate lack of eligibility for LTx, but older patients tend to have a worse survival due to comorbidities [6]. Vascular disease and occult malignancy are more common with age and most programmes attempt to define the extent of peripheral, cerebral and coronary vascular pathology in the older patient prior to listing. In the experience of the Dutch LTx programme, cardiovascular comorbidities were the most frequent reason for rejecting patients [4]. Routine coronary angiography for all prospective LTx candidates does not seem supported by studies to date, but selection of higher-risk patients based on smoking history, age and at least one other coronary artery disease risk factor is recommended $[7,8]$.

\section{Contraindictions}

Absolute contraindications to LTx [1] include serious dysfunction of the kidney and liver, active extrapulmonary infection, current tobacco use or other substance abuse (e.g. alcohol, narcotics), progressive neuromuscular disease and active malignancy within the past 2 yrs (with the exception of basal and squamous cell carcinoma of the skin). A 5-yr, disease-free interval is prudent for extracapsular renal cell tumours, breast cancer that is stage 2 or higher, colon cancer staged higher than Dukes A, and melanoma, level III or higher. A search for occult malignancy should be part of the routine pretransplant assessment (table 1), in particular in older patients. Of interest, serum carcinoembryonic antigen levels are often higher in patients with end-stage lung disease, especially idiopathic pulmonary fibrosis (IPF), and predict neither post-transplant survival nor development of malignancy [9].

Relative contraindications include medical conditions of the recipients that are felt to potentially impact on the longterm outcome and should be optimally treated and well controlled prior to surgery [1]. When they have not resulted in end-stage organ damage, diabetes mellitus, systemic hypertension and peptic ulcer disease are generally acceptable in candidates for LTx. Similarly, current use of corticosteroids is no longer a contraindication to transplantation, but all
Table 1. - Investigations

\begin{tabular}{|c|c|}
\hline \multirow[t]{11}{*}{ Blood tests } & Full blood count \\
\hline & Coagulation studies \\
\hline & Blood group \\
\hline & Urea, electrolytes, creatinine \\
\hline & Blood glucose \\
\hline & Liver function \\
\hline & Calcium and magnesium \\
\hline & Lipid profile \\
\hline & Thyroid function studies \\
\hline & HLA status \\
\hline & Panel reactive antibody status \\
\hline \multirow[t]{5}{*}{ Radiology studies } & Chest CT and/or CXR \\
\hline & Thoracoabdominal CT Scan \\
\hline & Abdominal ultrasound \\
\hline & $\begin{array}{l}\text { Ventilation/perfusion scan especially for } \\
\text { single LTx }\end{array}$ \\
\hline & Sinus CT (in cystic fibrosis) \\
\hline \multirow{12}{*}{ Functional studies } & Lung function \\
\hline & Spirometry, lung volumes and diffusion \\
\hline & $\begin{array}{l}\text { Maximal inspiratory and expiratory } \\
\text { pressures }\end{array}$ \\
\hline & Arterial blood gases \\
\hline & 6-min walk/3-min step test \\
\hline & Cardiac \\
\hline & ECG \\
\hline & Gated heart pool scan \\
\hline & Echocardiogram \\
\hline & Coronary angiography (see text) \\
\hline & Bone mineral density \\
\hline & $\begin{array}{l}\text { Polysomnogram (for } \mathrm{PH} \text {, respiratory } \\
\text { failure and right heart failure) }\end{array}$ \\
\hline \multirow[t]{9}{*}{ Infection screen } & Sputum $\mathrm{m} / \mathrm{c} / \mathrm{s}$, fungi and mycobacteria \\
\hline & Mantoux test \\
\hline & Midstream urine \\
\hline & Swabs for MRSA \\
\hline & Serology for HIV, hepatitis $\mathrm{B}$, hepatitis $\mathrm{C}$ \\
\hline & Serology for cytomegalovirus \\
\hline & Serology for Ebstein-Barr virus \\
\hline & Serology for Chlamydia pneumoniae \\
\hline & Serology for Varicella zoster \\
\hline \multirow[t]{5}{*}{ Malignancy screen } & Sputum cytology \\
\hline & Papanicolau smear \\
\hline & Prostate specific antigen \\
\hline & Mammography \\
\hline & Faecal occult blood screening \\
\hline \multirow[t]{7}{*}{ Autoimmune screen } & ANA \\
\hline & ENA \\
\hline & DNA antibody \\
\hline & Rheumatoid factor \\
\hline & ANCA \\
\hline & Creatine kinase \\
\hline & Immunoglobulins \\
\hline \multirow[t]{2}{*}{ Compliance screen } & Serum cotinine \\
\hline & Psychology profile \\
\hline \multirow{8}{*}{ Consultant referrals } & Dental \\
\hline & Gastroenterology \\
\hline & Dermatology \\
\hline & Psychiatry \\
\hline & Nutrition \\
\hline & Social work \\
\hline & Physiotherapy \\
\hline & Ear, nose and throat for cystic fibrosis \\
\hline
\end{tabular}

HLA: human leukocyte antigen; CT: computed tomography; CXR: chest radiograph; LTx: lung transplantation; ECG: electrocardiogram; PH: pulmonary hypertension; $\mathrm{m} / \mathrm{c} / \mathrm{s}$ : microscopy, culture and sensitivity testing; MRSA: methicillin-resistant Staphylococcus aureus; HIV: human immunodeficiency virus; ANA: antinuclear antibody; ENA: extractable nuclear antibody; DNA: deoxyribonucleic acid; ANCA: antineutrophilic cytoplasmic antibody. 
Table 2.-Comorbidities that increase risk of 1- and 5-yr mortality

\author{
Congenital heart disease \\ Retransplantation \\ Ventilator dependency \\ Total dependence in ADLS \\ In hospital or ICU \\ Primary pulmonary hypertension \\ Idiopathic pulmonary fibrosis/sarcoidosis \\ Advanced recipient age \\ Recipient $\mathrm{BMI} \geqslant 30$ \\ Recipient weight $\leqslant 40 \mathrm{~kg}$ \\ Centre transplant volume $\leqslant 10 \cdot \mathrm{yr}^{-1}$ \\ Bilirubin $\geqslant 50 \mathrm{mg} \cdot \mathrm{L}^{-1}$
}

ADLS: activities of daily living; ICU: intensive care unit; BMI: body mass index. Adapted from [5].

attempts to discontinue these drugs or at least reduce the dose to $<20 \mathrm{mg} \cdot \mathrm{day}^{-1}$ prednisone should be made. Osteoporosis is now recognised as a major risk factor for post-transplant bone fracture and diminished quality of life after LTx, which mandates early interventional therapy to preserve bone mass [10-12]. This should commence prior to transplant. Patients with a body mass index $(\mathrm{BMI})>25-30 \mathrm{~kg} \cdot \mathrm{m}^{-2}$ or $<18 \mathrm{~kg} \cdot \mathrm{m}^{-2}$ require either weight loss or weight gain, because morbid obesity and cachexia may be associated with increased postoperative mortality $[13,14]$. The effect of wasting, however, has not been found consistently [13], in particular in patients with cystic fibrosis $(\mathrm{CF})[15,16]$.

Selecting patients who require invasive ventilatory support or artificial assist devices, such as extracorporeal membrane oxygenation, adds a degree of urgency to donor acquisition, and clearly, is only a feasible undertaking where there is either local flexibility in waiting-list management, to accommodate the needs of critically ill candidates, or access to urgent donor organ requests. Many units consider that only patients who have been fully assessed and listed prior to the need for invasive mechanical ventilation should be considered as appropriate candidates for LTx. Status in hospital or in intensive care units (ICUs) and invasive mechanical ventilation are associated with less favourable 1- and 5-yr outcomes [5], although this may apply to a lesser extent to patients with $\mathrm{CF}$ [17]. Outcome data from patients on noninvasive ventilation are scant but this appears to be a preferable bridge to transplant where available $[18,19]$.

Potential candidates should demonstrate adequate health behaviour and willingness to develop a working therapeutic alliance with the transplant group. Poorly controlled psychoaffective disorders, inability to understand the complexities of the therapy or to comply with the complex medication regimen, and a documented history of noncompliance with medical care are all relative contraindications.

There are few data to guide practice in the area of solid organ transplantation in patients infected with hepatitis B and $\mathrm{C}$ and/or human immunodeficiency virus (HIV). Provided there is no significant liver disease, hepatitis B- or C-antigen positivity is no longer considered an absolute contraindication to LTx, but attempts to suppress viraemia prior to transplantation are advised [20,21]. Regarding patients with HIV, a recent sounding board article by HALPERN et al. [22] discusses the current practice and ethical considerations of transplantation. While most centres polled expressed concern regarding offering organs to HIV-positive patients, the authors argue persuasively that published reports to date suggest the presence of HIV infection per se does not negatively impact outcome from transplantation. Moreover, the risk of HIV transmission to caring staff is lower than hepatitis $\mathrm{C}$, and in the absence of evidence to suggest that patients with well-controlled HIV infection derive less benefit than recipients with other comorbidities, there is no justification for utilising less viable organs in this group. They suggested assessing the extent of HIV infection and making decisions as per the consideration of any other comorbidity until accumulating data provide information regarding the appropriateness or otherwise of transplantation in this group. Just as LTx is contraindicated in hepatitis C patients with established cirrhosis due to lack of enduring efficacy, the authors warrant that it is not appropriate to consider transplant in patients with terminal acquired immune deficiency syndrome. Importantly, the authors state that it is not the position of medicine to adjudicate the morality of personal behaviour through selective treatment of lifethreatening conditions. In the practical arena, these considerations may be relevant for HIV-related pulmonary hypertension that is refractory to medical therapies, and hepatitis C-positive patients with a distant past history of intravenous drug use of illicit substances. Each unit will develop its own strategies to manage these patient-care situations, but the above discussion provides a framework for ethical decision-making.

\section{Timing of referral}

\section{General recommendations}

It is generally recommended to consider transplantation when the patient is symptomatic during daily living activities (New York Heart Association (NYHA) class III or IV) and survival is expected to be limited to $2-3$ yrs, which represents the upper end of the usual waiting time [23]. The chance of surviving the waiting period will depend on the waiting time, the underlying disease and the existing system for allocation of donor organs. The waiting time tends to be longer for heart LTx, compared with single LTx, for small females compared with taller patients, and for recipients with blood groups other than AB [24]. Waiting time also tends to be longer at large-size transplant programmes [25]. The primary disease of the recipient has a major impact on waiting-list mortality; patients with IPF, CF, and primary pulmonary hypertension (PPH) have lower survival rates while awaiting LTx than patients with emphysema or Eisenmenger's syndrome [25-27]. The difficulty of prognosticating survival, however, is a major factor confounding the issue of timing of referral, and the high mortality on the waiting list for patients with IPF and $\mathrm{CF}$ suggests that referrals tend to occur too late in the evolution of the disease process.

The transplant literature is heavily weighted towards a decision-making process regarding organ allocation that relies on the implicit assumption that there is equity of access to LTx services, equity of timing of referral within and between disease states, and critically, equity of a "time-waited" approach to the distribution of donor organs [25]. These assumptions are not supported by an analysis of outcome data. The differential waiting-list mortality between IPF or $\mathrm{CF}$ and emphysema, alone, attests to the inequity of this approach. For this reason, prioritisation on the waiting list according to the recipient's primary disease is increasingly considered as a step forward towards a more equitable allocation of donor lungs [26, 28]; in the United Network for Organ Sharing of the USA, patients with IPF are currently assigned a bonus of 90 days of waiting time upon registration on the active list.

Early referral for consideration of LTx is highly desirable. It allows an orderly process of assessment and management of areas of concern prior to active listing. Issues pertaining to the psychology of accepting and confronting a life-threatening 
illness can be addressed over an appropriate period of time. Furthermore, early referral probably enhances an individual patient's chance of surviving to transplant and minimises the trauma and distress of waiting while desperately ill. Indeed, evidence now suggests a reduced survival post-LTx for that cohort of patients who, by these delays, become totally dependent, hospital bound, malnourished and debilitated. Rather than merely surviving to transplant with the aid of mechanical and physical-assist devices, the waiting period can be used productively to actively manage healthcare needs by a multidisciplinary transplant team with expertise and experience in specific risk-factor management pretransplant [29]. It is this area where the simple paradigm of "passive" waiting on the transplant list has so altered in recent years towards an "active" prescription of therapies designed to optimise time utilisation while waiting. Conversely, late referral [30] compromises the likely outcomes achievable within a realistic time-frame and, in a sense, becomes a self-fulfilling prophecy for those who do not believe in the positive benefits that can and do accrue from LTx. Late referral definitely reduces the chance of surviving to transplant and is associated with heightened patient anxiety scores while waiting.

\section{Survival benefit}

The implicit rationale behind existing recommendations regarding timing of referral is that the primary goal of LTx is to provide a survival benefit, i.e. post-transplant survival should exceed the expected survival without the procedure. Several studies in adults [31-35] and children [36] have assessed survival benefit by comparing survival on the waiting list with survival after LTx. They found that LTx may confer a significant survival benefit [31], in particular in patients with $\mathrm{CF}$, IPF and PPH [32-35]; two studies [33, 34] reported a similar observation for emphysema patients but one did not [32] and two studies that assessed patients with Eisenmenger's syndrome $[33,34]$ did not find any survival benefit with LTx. The significance of these results, however, is limited by uncertainties regarding the methodology [31] and the validity of several assumptions used in the analysis, which preclude any firm conclusion as to whether LTx may be justified or not. In addition, there is much ongoing discussion on how to weigh expected survival benefits with gains in quality of life, i.e. it may be unsound to compare a year of survival under extremely difficult conditions with a year spent enjoying a dramatic improvement in quality of life. LTx for many patients will be a palliative treatment rather than a definitive cure, and thus it may be sound to include measurements of quality of life, in addition to survival, when assessing the effectiveness of the procedure [37]. This view is shared by the patients themselves [38].

\section{Disease-specific considerations}

This section discusses disease-specific predictors of survival that may be used in the decision-making process of when a patient should be listed for LTx [39]. It is important to stress that this decision should not be based on a single factor because no simple single-point determinant is sufficiently predictive of early mortality to provide a robust indication for timing of referral. Rather, it is recommended that a variety of clinical (e.g. quality of life, rate of infection, ICU hospitalisation, oxygen need, weight loss, etc.), laboratory (e.g. arterial oxygen tension $\left(\mathrm{Pa}_{\mathrm{a}} \mathrm{O}_{2}\right)$ and arterial carbon dioxide tension $\left.\left(P \mathrm{a}, \mathrm{CO}_{2}\right)\right)$ and functional findings (e.g. pulmonary function tests, echocardiogram, exercise capacity) are used. Predictors of survival are discussed for the diseases that are the primary indications for LTx [5]: emphysema, either primarily related to smoking $(39.4 \%)$ or secondarily related to smoking $\left(\alpha_{1}\right.$-antitrypsin deficiency $\left.9.3 \%\right)$, IPF $(16.9 \%)$, CF $(16.1 \%)$ and PPH $(4.6 \%)$.

\section{Chronic obstructive pulmonary disease}

The availability of lung volume reduction surgery (LVRS) may influence the decision to list an individual patient but the majority are not suitable for both procedures, and patients who are sufficiently disabled by poor lung function to warrant consideration of LTx fall into the high-risk group for LVRS $[40,41]$. Nevertheless, a number of programmes have found that the option of LVRS allowed deferral of patients who were previously listed for LTx [42]. LVRS does not appear to be associated with acceptable short-term outcomes for patients with a forced expiratory volume in one second (FEV1) $<20 \%$ predicted and either homogeneous emphysema or a diffusing capacity for carbon monoxide ( $D \mathrm{~L}, \mathrm{CO})<20 \%$ pred, hypercapnia, pulmonary hypertension and/or $\alpha_{1^{-}}$ antitrypsin deficiency [43]. A limited experience with synchronous combined LVRS and LTx has been described as an alternative approach in selected patients [44].

The definition of an appropriate timing of referral for patients with chronic obstructive pulmonary disease (COPD) is complicated by the fact that very symptomatic patients may have a relatively good prognosis. Among COPD patients, those with a "chronic asthmatic bronchitis" type of disease have a much better outcome than those with emphysema [45]. Hospitalisation for exacerbation of COPD associated with hypercapnia carries a poor prognosis with a 49\% 2-yr mortality [46]. Survival rates decrease as age, the degree of hypoxaemia and hypercapnia, and pulmonary artery pressure increase, and as FEV1, DL,CO, BMI and inspiratory muscle strength decrease [1, 47, 48]. In addition, measures of health-related quality of life are independent risk factors of mortality [47].

\section{Idiopathic pulmonary fibrosis}

Most patients with IPF are referred late for transplant and this contributes to the high waiting-list mortality. The usual interstitial pneumonia (UIP) pattern of IPF is generally unresponsive to steroid therapy and median survival after this diagnosis is only $2.8 \mathrm{yrs}$ [49]. It is not generally recognised that among common pulmonary disorders, only lung cancer has a lower 5-yr survival rate from diagnosis. In the international document [1], it was recommended that symptomatic patients with IPF should be referred to a transplant centre in any of the following circumstances: progressive disease with failure to improve or maintain lung function while being treated with steroids or other immunosuppressive agents, DL,CO $<50-60 \%$ pred, forced vital capacity $<60-70 \%$ pred, resting hypoxaemia or pulmonary hypertension. In a single centre study of 115 patients of $<65$ yrs of age with UIP, the DL,CO and high-resolution computed tomography (HRCT) score for fibrosis were found to be independent predictors of 2-yr mortality [50]. The optimal values on a receiver-operating characteristic curve (ROC) for discriminating between survivors and nonsurvivors corresponded to a DL,CO of 39\% pred and an HRCT fibrosis score of 2.25. Combining these two parameters gave a specificity and sensitivity of 84 and $82 \%$, respectively.

\section{Cystic fibrosis}

The issue of antibiotic sensitivity testing and suitability for transplant remains unresolved due to the lack of comprehensive 
data regarding outcomes of transplanting patients with panresistant versus multiresistant organisms. Each unit is recommended to develop its own policy but recent singlecentre reports point to a higher mortality rate in $\mathrm{CF}$ patients infected with Burkholderia cepacia complex genomovar III; specifically, a $30-40 \%$ difference in survival at 1 [51] and 3 [52] yrs in the infected versus the noninfected group. Multicentre studies to confirm the level of risk attached to this organism, in particular, have not been done. The possibility of utilising in vitro synergy testing to identify the optimum antibiotic therapy has been discussed but is not yet widely practiced. The pretransplant presence of multidrug-resistant Pseudomonas aeruginosa has no significant influence on outcome [53].

Defining appropriate criteria for referral of CF patients for LTx is difficult because the course and prognosis of the disease are highly variable between individuals. The individual's unique medical characteristics often make it difficult to apply statistical models to specific patients. In addition, such models are derived from longitudinal studies involving large groups of patients with progressive, fatal pulmonary processes; such studies are difficult to perform and few in numbers. The guidelines proposed in the international consensus document [1] were primarily based on the study by KEREM et al. [54] who identified an FEV1 $<30 \%$ pred (and to a lesser extent, a $\mathrm{Pa}, \mathrm{CO}_{2}>7.3 \mathrm{kPa}(55 \mathrm{mmHg})$, a $\mathrm{Pa}, \mathrm{O}_{2}$ $<6.65 \mathrm{kPa}(50 \mathrm{mmHg})$, aged $<18 \mathrm{yrs}$ and female) as a useful marker for predicting survival. Several subsequent studies [15, 55-57], commented on in at least two editorials [58, 59], emphasised that no threshold FEV1 value (e.g. $<30 \%$ [54] or $50 \%$ [60] pred) can be considered on its own as a robust predictor of survival and be used to recommend referral.

Physiological variables other than those derived from standard pulmonary function tests and blood-gas data may contribute to assess prognosis in CF patients and assist in the process of listing. A measure of exercise performance is used by most transplant centres. Recently, it was shown that an elevated breathing reserve index (minute ventilation/maximal voluntary ventilation) at the lactate threshold, as well as resting $\mathrm{Pa}_{\mathrm{a}} \mathrm{CO}_{2}$ and $\mathrm{FEV} 1 \%$ pred, are independent risk factors for mortality [61]. In children with CF, the 3-min step test is a suitable and possibly superior tool when compared with the traditional 6-min walk test [62]; furthermore, it is easy to learn and administer and can be performed routinely at outpatient follow-up.

In another study [63], resting hypercapnia and increased perfusion disparity (i.e. severe, unilateral perfusion abnormality), on lung ventilation/perfusion scans, were the main predictors of death identified by the Cox model. Pulmonary haemodynamics may also provide useful prognostic indications. In a small single-centre study, VENUTA and co-workers $[64,65]$ found that for patients already waiting for LTx, an elevated $\mathrm{Pa}, \mathrm{CO}_{2}$, resting heart rate, mean pulmonary artery pressure (mPAP), pulmonary vascular resistance and increased cardiac index were associated with an increased risk of death on the waiting list. Importantly, pulmonary haemodynamics deteriorated significantly during the time waited. The importance of pulmonary hypertension as a prognostic factor has also been reported in a study that used Doppler echocardiography [66]; it should be stressed, however, that in patients with pulmonary hypertension awaiting LTx, technical limitations of the echocardiogram often preclude estimating pulmonary artery systolic pressure [67].

Many of the above-mentioned studies came from single centres and included a small number of subjects. To overcome these limitations that preclude generalisation to the entire $\mathrm{CF}$ population, several investigators have developed larger inclusive models using multivariate Cox regression analysis to predict survival in adults and children with CF [57, 68-72]. The models included a variety of anthropometric, physiological, laboratory and clinical characteristics (e.g. microbiology, number of hospitalisations or intravenous antibiotic treatment, presence of diabetes mellitus and malabsorption). Unfortunately, these studies have provided inconsistent results that probably reflect the heterogeneous nature of $\mathrm{CF}$; although FEV1 (\% pred) was usually found to be an independent risk factor for mortality, the impact of other factors, such as sex, nutritional status, respiratory secretions, microbiology, diabetes mellitus, hypercapnia or pulmonary artery pressure, was variable. Validation of the models showed a good fit between expected and observed probabilities, and ROC curves constructed in two studies [69, 70] demonstrated good diagnostic accuracy. However, even with a good sensitivity, a model may have a limited positive predictive value if the mortality of the cohort studied is low (i.e. a substantial proportion of patients predicted to die will actually survive); this limitation obviously decreases the usefulness of the model in optimising the timing of listing for individual patients [70]. The applicability of the models is further limited by the lack of prospective validation. Thus, at present, no firm recommendation can be made regarding what combination of factors (and what thresholds) should be used when deciding if transplant referral or listing is appropriate. The final decision must derive from a comprehensive evaluation that should take into account indicators of disease severity, recipient characteristics that may impact on waiting time (see above), average local waiting time, and whether or not the organ allocation policy permits prioritisation for medical urgency. Physicians and patients must be aware that many $\mathrm{CF}$ patients die while awaiting LTx, indicating that referral often occurs too late in the course of their disease [30, 73]. Unfortunately, available studies demonstrate that the use of the FEV1 criterion or more complex models cannot discriminate patients who are likely to survive from those who are likely to die, and may result in premature referral [15, 55-57, 70]. Prediction models may be of greater help to identify patients who are not ill enough to require transplant surgery; the reported high negative predictive value [70] indicating that the models can more accurately predict survival than death.

\section{Primary pulmonary hypertension}

In recent years, the management of patients with PPH has considerably evolved due to the availability of new medical therapies [74]. Following the study by D'Alonzo et al. [75], haemodynamic variables were believed to provide clinicians with strong prognostic factors. Elevated right atrial or mPAPs, along with decreased cardiac output were associated with a worse prognosis. However, these data from the US national registry were collected in the pre-prostaglandin $(\mathrm{PG}) \mathrm{I}_{2}$ era. More recent studies indicate that functional capacity, as assessed by measurement of the 6-min walking distance, appears to be a strong predictor of mortality in patients with PPH [76-78], a 6-min walking distance of $<332 \mathrm{~m}$ being associated with a poor prognosis [79].

The long-term effects of chronic medical therapy for PPH is an area of important controversy. A consistent decrease in mortality has recently been reported with chronic intravenous epoprostenol for PPH by two leading centres [76, 77], both showing significant improvement in survival rate up to 85,70 and $60 \%$ at 1,2 and 3 yrs, respectively. Moreover, the $55 \%$ survival rate at 5 yrs demonstrated in the French study [77] is slightly above the expected survival after LTx. Whether or not the survival benefit of chronic intravenous epoprostenol can be extrapolated to the newer $\mathrm{PGI}_{2}$ derivates is still unknown. Long-term data are missing, but clinical and functional 
improvements appear to be sustained with some $\mathrm{PGI}_{2}$ analogues, such as treprostinil [79].

A modern management strategy for PPH has been proposed recently, taking into account the most recent advances in medical treatment [80]. Although there is probably a place for each drug, $\mathrm{PGI}_{2}$ derivates, such as epoprostenol, iloprost or treprostinil appear best suited for bridging patients to LTx. However, it is still unclear whether or not patients in NYHA IV should be listed for LTx before attempting medical therapy and whether or not patients not responding to treprostinil or inhaled iloprost should be converted to epoprostenol before being listed. Atrial septostomy should be strongly considered in experienced centres, either when patients are listed for transplantation or when medical therapy is insufficient to maintain exercise tolerance or relieve symptoms. Finally, results of each intervention should be assessed on a regular schedule, usually every 3 months or earlier in case of clinical or functional deterioration, and listing for transplantation should be decided on functional, haemodynamic and clinical criteria (table 3 ).

Pulmonary thromboendarterectomy has advantages over LTx for chronic thromboembolic pulmonary hypertension, such as superior short-term survival and the lack of need for long-term immunosuppressive therapy, and thus it is considered a favoured alternative where available [81].

\section{Conclusion}

Evidence is slowly accumulating to guide practice in the area of candidate selection for lung transplantation. The

Table 3. - Timing of referral

\begin{tabular}{|c|c|}
\hline Cystic fibrosis & $\begin{array}{l}\mathrm{FEV} 1<30 \% \text { pred } \\
\mathrm{PCO}_{2}>50 \mathrm{mmHg} \\
\mathrm{PO}_{2}<55 \mathrm{mmHg} \\
\text { Rapid decline in FEV1 } \\
\text { Clinical deterioration } \\
\text { Frequent hospitalisation } \\
\text { Massive haemoptysis } \\
\text { Recurrent pneumothoraces } \\
\text { Wasting } \\
\text { Young females with rapid } \\
\text { deterioration }\end{array}$ \\
\hline Pulmonary fibrosis & $\begin{array}{l}\text { Failure to maintain lung function } \\
\text { while being treated with } \\
\text { steroids/immunosuppressive agents } \\
\text { Resting hypoxaemia } \\
\text { Pulmonary hypertension } \\
D \text { L,CO }<40 \% \text { pred } \\
\text { HRCT score }>2.25\end{array}$ \\
\hline Emphysema & $\begin{array}{l}\mathrm{FEV} 1<20 \% \text { pred } \\
\mathrm{PCO}_{2}>6.0 \mathrm{kPa} \\
\text { Homogeneous distribution } \\
\text { Pulmonary hypertension }\end{array}$ \\
\hline Pulmonary hypertension & $\begin{array}{l}\text { Functional status } \\
\text { NYHA class III or IV } \\
\text { Low exercise tolerance (SMWD } \\
<350 \mathrm{~m} \text { ) } \\
\text { Uncontrolled syncope, haemoptysis } \\
\text { or right heart failure } \\
\text { Useful haemodynamic variables } \\
\text { Cardiac index }<2 \mathrm{~L} \cdot \mathrm{min}^{-1} \cdot \mathrm{m}^{-2} \\
\text { Right atrial pressure }>15 \mathrm{mmHg} \\
S_{\mathrm{v}, \mathrm{O}_{2}}<60 \%\end{array}$ \\
\hline
\end{tabular}

FEV1: forced expiratory volume in one second; $\mathrm{PCO}_{2}$ : carbon dioxide tension; $\mathrm{PO}_{2}$ : oxygen tension; $\mathrm{DL}, \mathrm{CO}$ : diffusing capacity of carbon monoxide; HRCT: high-resolution computed tomography; NYHA: New York Heart Association; SMWD: 6-min walking distance; $S_{\mathrm{v}}, \mathrm{O}_{2}$ : venous saturation. quality of the evidence, however, remains low, as most studies are either underpowered or single-centre reports or both. Areas that bear further scrutiny include the best selection criteria for cystic fibrosis, where the referring community needs to be disabused of the notion that forced expiratory volume in one second is the sole criterion in which transplant centres are interested to determine listing. Referrals occur late in the disease process in idiopathic pulmonary fibrosis and cystic fibrosis with a resultant excess mortality on the waiting list in the order of $20 \%$ of prospective candidates. Educational strategies are needed to promote the benefits of early referral. Active management of identified comorbidities during the waiting period works to the immediate and potential advantage of the recipient. Ultimately, quality-of-life issues are commonly utilised by referring physicians as determinants of when to refer, and it behoves the lung transplantation community to work closely with the referral community to provide up-to-date and robust estimates of likely outcomes so that individual patients are well informed of the myriad benefits that successful lung transplantation can provide.

\section{References}

1. Maurer JR, Frost AE, Estenne M, Higenbottam T, Glanville AR. International guidelines for the selection of lung transplant candidates. The International Society for Heart and Lung Transplantation, the American Thoracic Society, the American Society of Transplant Physicians, the European Respiratory Society. J Heart Lung Transplant 1998; 17: 703-709.

2. Marshall SE, Kramer MR, Lewiston NJ, Starnes VA, Theodore J. Selection and evaluation of recipients for heart-lung and lung transplantation. Chest 1990; 98: 14881494.

3. Smith CM. Patient selection, evaluation, and preoperative management for lung transplant candidates. Clin Chest Med 1997; 18: 183-197.

4. Mannes GP, de Boer WJ, van der Bij W, Grevink RG, Koeter GH. Three hundred patients referred for lung transplantation. Experiences of the Dutch Lung Transplantation Program. Groningen Lung Transplantation Group. Chest 1996; 109: 408-413.

5. Hertz MI, Taylor DO, Trulock EP, et al. The registry of the international society for heart and lung transplantation: nineteenth official report-2002. J Heart Lung Transplant 2002; 21: 950-970.

6. Snell GI, De Hoyos A, Winton T, Maurer JR. Lung transplantation in patients over the age of 50. Transplantation 1993; 55: 562-566.

7. Leibowitz DW, Caputo AL, Shapiro GC, et al. Coronary angiography in smokers undergoing evaluation for lung transplantation: is routine use justified? J Heart Lung Transplant 1994; 13: 701-703.

8. Thaik CM, Semigran MJ, Ginns L, Wain JC, Dec GW. Evaluation of ischemic heart disease in potential lung transplant recipients. J Heart Lung Transplant 1995; 14: 257-266.

9. Hadjiliadis D, Tapson VF, Davis RD, Palmer SM. Prognostic value of serum carcinoembryonic antigen levels in patients who undergo lung transplantation. J Heart Lung Transplant 2001; 20: 1305-1309.

10. Aris RM, Neuringer IP, Weiner MA, Egan TM, Ontjes D. Severe osteoporosis before and after lung transplantation. Chest 1996; 109: 1176-1183.

11. Shane E, Papadopoulos A, Staron RB, et al. Bone loss and fracture after lung transplantation. Transplantation 1999; 68: 220-227.

12. Dodd VA, Staron RB, Papadopoulos A, et al. Bone densitometry should be included in the evaluation of 
candidates for lung transplantation. J Transpl Coord 1999; 9: 119-123.

13. Kanasky WF Jr, Anton SD, Rodrigue JR, Perri MG, Szwed $\mathrm{T}$, Baz MA. Impact of body weight on long-term survival after lung transplantation. Chest 2002; 121: 401-406.

14. Madill J, Gutierrez C, Grossman J, et al. Nutritional assessment of the lung transplant patient: body mass index as a predictor of 90-day mortality following transplantation. J Heart Lung Transplant 2001; 20: 288-296.

15. Doershuk CF, Stern RC. Timing of referral for lung transplantation for cystic fibrosis: overemphasis on FEV1 may adversely affect overall survival. Chest 1999; 115: 782787.

16. Snell GI, Bennetts K, Bartolo J, et al. Body mass index as a predictor of survival in adults with cystic fibrosis referred for lung transplantation. J Heart Lung Transplant 1998; 17: 1097-1103.

17. Sood N, Paradowski LJ, Yankaskas JR. Outcomes of intensive care unit care in adults with cystic fibrosis. $\mathrm{Am}$ J Respir Crit Care Med 2001; 163: 335-338.

18. O'Brien G, Criner GJ. Mechanical ventilation as a bridge to lung transplantation. J Heart Lung Transplant 1999; 18: 255-265.

19. Madden BP, Kariyawasam H, Siddiqi AJ, Machin A, Pryor JA, Hodson ME. Noninvasive ventilation in cystic fibrosis patients with acute or chronic respiratory failure. Eur Respir $J$ 2002; 19: 310-313.

20. Fried MW, Shiffman ML, Reddy KR, et al. Peginterferon alfa-2a plus ribavirin for chronic hepatitis $\mathrm{C}$ virus infection. $N$ Engl J Med 2002; 347: 975-982.

21. Jonas MM, Kelly DA, Mizerski J, et al. Clinical trial of lamivudine in children with chronic hepatitis B. N Engl J Med 2002; 346: 1706-1713.

22. Halpern SD, Ubel PA, Caplan AL. Solid-organ transplantation in HIV-infected patients. N Engl J Med 2002; 347: 284 287.

23. Arcasoy SM, Kotloff RM. Lung transplantation. $N$ Engl J Med 1999; 340: 1081-1091.

24. De Meester J, Smits JM, Persijn GG, Haverich A. Lung transplant waiting list: differential outcome of type of endstage lung disease, one year after registration. J Heart Lung Transplant 1999; 18: 563-571.

25. Pierson RN, Milstone AP, Loyd JE, Lewis BH, Pinson CW, Ely EW. Lung allocation in the United States, 1995-1997: an analysis of equity and utility. J Heart Lung Transplant 2000; 19: 846-851.

26. Ouwens JP, Groen H, TenVergert EM, Koeter GH, de Boer $\mathrm{WJ}$, van der Bij W. Simulated waiting list prioritization for equitable allocation of donor lungs. J Heart Lung Transplant 2002; 21: 797-803.

27. D'Armini AM, Callegari G, Vitulo P, et al. Risk factors for early death in patients awaiting heart-lung or lung transplantation: experience at a single European center. Transplantation 1998; 66: 123-127.

28. Dark JH. Priorities for lung transplantation. Lancet 1998; 351: 4-5.

29. Gabbay E, Dark JH, Wrightson N, Corris PA. Lung transplantation in patients with cystic fibrosis. Thorax 1996; 51: 1068.

30. Studer SM, Krishnan JA, Orens JB. Indications for lung transplant referral: physician attitudes. $J$ Heart Lung Transplant 2002; 21: 716-717.

31. Geertsma A, Ten Vergert EM, Bonsel GJ, de Boer WJ, van der Bij W. Does lung transplantation prolong life? A comparison of survival with and without transplantation. J Heart Lung Transplant 1998; 17: 511-516.

32. Hosenpud JD, Bennett LE, Keck BM, Edwards EB, Novick RJ. Effect of diagnosis on survival benefit of lung transplantation for end-stage lung disease. Lancet 1998; 351: 24-27.

33. De Meester J, Smits JM, Persijn GG, Haverich A. Listing for lung transplantation: life expectancy and transplant effect, stratified by type of end-stage lung disease, the Eurotransplant experience. J Heart Lung Transplant 2001; 20: 518-524.

34. Charman SC, Sharples LD, McNeil KD, Wallwork J. Assessment of survival benefit after lung transplantation by patient diagnosis. J Heart Lung Transplant 2002; 21: 226232.

35. Liou TG, Adler FR, Cahill BC, et al. Survival effect of lung transplantation among patients with cystic fibrosis. JAMA 2001; 286: 2683-2689.

36. Aurora $\mathrm{P}$, Whitehead $\mathrm{B}$, Wade A, et al. Lung transplantation and life extension in children with cystic fibrosis. Lancet 1999; 354: 1591-1593.

37. Kesten S. Is survival that important? J Heart Lung Transplant 1998; 17: 651-653.

38. Maish AB. Priorities for lung transplantation among patients with cystic fibrosis. JAMA 2002; 287: 1524-1525.

39. Edelman JD, Kotloff RM. Lung transplantation. A diseasespecific approach. Clin Chest Med 1997; 18: 627-644.

40. Cordova FC, Criner GJ. Surgery for chronic obstructive pulmonary disease: the place for lung volume reduction and transplantation. Curr Opin Pulm Med 2001; 7: 93-104.

41. Meyers BF, Patterson GA. Lung transplantation versus lung volume reduction as surgical therapy for emphysema. World J Surg 2001; 25: 238-243.

42. Bavaria JE, Pochettino A, Kotloff RM, et al. Effect of volume reduction on lung transplant timing and selection for chronic obstructive pulmonary disease. $J$ Thorac Cardiovasc Surg 1998; 115: 9-18.

43. Patients at high risk of death after lung-volume-reduction surgery. N Engl J Med 2001; 345: 1075-1083.

44. Waddell TK, Keshavjee S. Lung transplantation for chronic obstructive pulmonary disease. Semin Thorac Cardiovasc Surg 1998; 10: 191-201.

45. Burrows B, Bloom JW, Traver GA, Cline MG. The course and prognosis of different forms of chronic airways obstruction in a sample from the general population. $N$ Engl J Med 1987; 317: 1309-1314.

46. Connors AF Jr, Dawson NV, Thomas C, et al. Outcomes following acute exacerbation of severe chronic obstructive lung disease. The SUPPORT investigators (Study to Understand Prognoses and Preferences for Outcomes and Risks of Treatments). Am J Respir Crit Care Med 1996; 154: 959-967.

47. Domingo-Salvany A, Lamarca R, Ferrer M, et al. Healthrelated quality of life and mortality in male patients with chronic obstructive pulmonary disease. Am J Respir Crit Care Med 2002; 166: 680-685.

48. Gray-Donald K, Gibbons L, Shapiro SH, Macklem PT, Martin JG. Nutritional status and mortality in chronic obstructive pulmonary disease. Am J Respir Crit Care Med 1996; 153: 961-966.

49. Bjoraker JA, Ryu JH, Edwin MK, et al. Prognostic significance of histopathologic subsets in idiopathic pulmonary fibrosis. Am J Respir Crit Care Med 1998; 157: 199-203.

50. Mogulkoc N, Brutsche MH, Bishop PW, Greaves SM, Horrocks AW, Egan JJ. Pulmonary function in idiopathic pulmonary fibrosis and referral for lung transplantation. $\mathrm{Am}$ J Respir Crit Care Med 2001; 164: 103-108.

51. Chaparro C, Maurer J, Gutierrez C, et al. Infection with Burkholderia cepacia in cystic fibrosis: outcome following lung transplantation. Am J Respir Crit Care Med 2001; 163 : 43-48.

52. Aris RM, Routh JC, LiPuma JJ, Heath DG, Gilligan PH. Lung transplantation for cystic fibrosis patients with Burkholderia cepacia complex. Survival linked to genomovar type. Am J Respir Crit Care Med 2001; 164: 2102-2106.

53. Aris RM, Gilligan PH, Neuringer IP, Gott KK, Rea J, Yankaskas JR. The effects of panresistant bacteria in cystic fibrosis patients on lung transplant outcome. Am J Respir Crit Care Med 1997; 155: 1699-1704.

54. Kerem E, Reisman J, Corey M, Canny GJ, Levison H. Prediction of mortality in patients with cystic fibrosis. $N$ Engl J Med 1992; 326: 1187-1191. 
55. Milla CE, Warwick WJ. Risk of death in cystic fibrosis patients with severely compromised lung function. Chest 1998; 113: 1230-1234.

56. Augarten A, Akons $\mathrm{H}$, Aviram M, et al. Prediction of mortality and timing of referral for lung transplantation in cystic fibrosis patients. Pediatr Transplant 2001; 5: 339-342.

57. Liou TG, Adler FR, Fitzsimmons SC, Cahill BC, Hibbs JR, Marshall BC. Predictive 5-year survivorship model of cystic fibrosis. Am J Epidemiol 2001; 153: 345-352.

58. Flume PA. Cystic fibrosis: when to consider lung transplantation? Chest 1998; 113: 1159-1161.

59. Maurer JR. Patient selection for lung transplantation. JAMA 2001; 286: 2720-2721.

60. Robinson W, Waltz DA. FEV(1) as a guide to lung transplant referral in young patients with cystic fibrosis. Pediatr Pulmonol 2000; 30: 198-202.

61. Tantisira KG, Systrom DM, Ginns LC. An elevated breathing reserve index at the lactate threshold is a predictor of mortality in patients with cystic fibrosis awaiting lung transplantation. Am J Respir Crit Care Med 2002; 165: 1629-1633.

62. Aurora P, Prasad SA, Balfour-Lynn IM, Slade G, Whitehead B, Dinwiddie R. Exercise tolerance in children with cystic fibrosis undergoing lung transplantation assessment. Eur Respir J 2001; 18: 293-297.

63. Stanchina ML, Tantisira KG, Aquino SL, Wain JC, Ginns LC. Association of lung perfusion disparity and mortality in patients with cystic fibrosis awaiting lung transplantation. J Heart Lung Transplant 2002; 21: 217-225.

64. Venuta F, Rendina EA, De Giacomo T, et al. Timing and priorities for cystic fibrosis patients candidates to lung transplantation. Eur J Pediatr Surg 1998; 8: 274-277.

65. Venuta F, Rendina EA, Rocca GD, et al. Pulmonary hemodynamics contribute to indicate priority for lung transplantation in patients with cystic fibrosis. $J$ Thorac Cardiovasc Surg 2000; 119: 682-689.

66. Fraser KL, Tullis DE, Sasson Z, Hyland RH, Thornley KS, Hanly PJ. Pulmonary hypertension and cardiac function in adult cystic fibrosis: role of hypoxemia. Chest 1999; 115: 1321-1328.

67. Homma A, Anzueto A, Peters JI, et al. Pulmonary artery systolic pressures estimated by echocardiogram vs cardiac catheterization in patients awaiting lung transplantation. J Heart Lung Transplant 2001; 20: 833-839.

68. Hayllar KM, Williams SG, Wise AE, et al. A prognostic model for the prediction of survival in cystic fibrosis. Thorax 1997; 52: 313-317.

69. Sharma R, Florea VG, Bolger AP, et al. Wasting as an independent predictor of mortality in patients with cystic fibrosis. Thorax 2001; 56: 746-750.

70. Mayer-Hamblett N, Rosenfeld M, Emerson J, Goss CH, Aitken ML. Developing cystic fibrosis lung transplant referral criteria using predictors of 2-year mortality. $\mathrm{Am}$ $J$ Respir Crit Care Med 2002; 166: 1550-1555.

71. Vizza CD, Yusen RD, Lynch JP, Fedele F, Alexander Patterson G, Trulock EP. Outcome of patients with cystic fibrosis awaiting lung transplantation. Am J Respir Crit Care Med 2000; 162: 819-825.

72. Aurora P, Wade A, Whitmore P, Whitehead B. A model for predicting life expectancy of children with cystic fibrosis. Eur Respir J 2000; 16: 1056-1060.

73. Ciriaco P, Egan TM, Cairns EL, Thompson JT, Detterbeck FC, Paradowski LJ. Analysis of cystic fibrosis referrals for lung transplantation. Chest 1995; 107: 1323-1327.

74. Rubin LJ. Primary pulmonary hypertension. $N$ Engl J Med 1997; 336: 111-117.

75. D'Alonzo GE, Barst RJ, Ayres SM, et al. Survival in patients with primary pulmonary hypertension. Results from a national prospective registry. Ann Intern Med 1991; 115: 343-349.

76. McLaughlin VV, Shillington A, Rich S. Survival in primary pulmonary hypertension: the impact of epoprostenol therapy. Circulation 2002; 106: 1477-1482.

77. Sitbon O, Humbert $\mathrm{M}$, Nunes $\mathrm{H}$, et al. Long-term intravenous epoprostenol infusion in primary pulmonary hypertension: prognostic factors and survival. $\mathrm{J} \mathrm{Am} \mathrm{Coll}$ Cardiol 2002; 40: 780-788.

78. Miyamoto S, Nagaya N, Satoh T, et al. Clinical correlates and prognostic significance of six-minute walk test in patients with primary pulmonary hypertension. Comparison with cardiopulmonary exercise testing. Am J Respir Crit Care Med 2000; 161: 487-492.

79. Badesch DB, Tapson VF, McGoon MD, et al. Continuous intravenous epoprostenol for pulmonary hypertension due to the scleroderma spectrum of disease. A randomized, controlled trial. Ann Intern Med 2000; 132: 425-434.

80. Hoeper MM, Galie N, Simonneau G, Rubin LJ. New treatments for pulmonary arterial hypertension. Am J Respir Crit Care Med 2002; 165: 1209-1216.

81. D'Armini AM, Cattadori B, Monterosso C, et al. Pulmonary thromboendarterectomy in patients with chronic thromboembolic pulmonary hypertension: hemodynamic characteristics and changes. Eur J Cardiothorac Surg 2000; 18: 696-702. 